\title{
TIME-RESOLVED BURNING OF SOLID FUELS FOR HYBRID ROCKET PROPULSION
}

\section{T. DeLuca, L. Galfetti, G. Colombo, F. Maggi, A. Bandera, M. Boiocchi, G. Gariani, L. Merotto, C. Paravan, and A. Reina}

\author{
Politecnico di Milano \\ Aerospace Engineering Department \\ Via La Masa 34, Milan, Italy
}

Features such as lowcost, safety, throttleability, and a wide range of appealing applications (e.g., interplanetary landers, boosters for space launcher, upper stage for Vega launcher) make hybrid rocket engines a very attractive option for aerospace propulsion. However, problems such as low regression rates of the solid fuel and low combustion efficiency have so far hindered the development of large-scale hybrid rocket engines. Space Propulsion Laboratory (SPLab) at Politecnico di Milano has developed a series of proprietary techniques to evaluate, on a relative grading, the quasi-steady regression rates of solid fuels while visualizing at the same time the flame structure. Numerical modeling, thermochemical calculations, and mechanical testing complete the range of tools set up to assess the quality of new solid fuels. In this paper, HTPB polymer has been taken as baseline and characterized at laboratory level.

\section{NOMENCLATURE}

\section{Latin Symbols}

A multiplier factor in Eq. (1), $\mathrm{mm} / \mathrm{s}^{n}$

$A_{b} \quad$ burning area, $\mathrm{mm}^{2}$

$A_{e} \quad$ nozzle exit area, $\mathrm{m}^{2}$

$A_{t} \quad$ nozzle throat area, $\mathrm{m}^{2}$

$D \quad$ diameter, mm

$D_{0} \quad$ initial diameter, $\mathrm{mm}$

$\bar{D}_{i} \quad$ sampled average diameter, $\mathrm{mm}$

$D_{h, i} \quad$ sampled horizontal diameter, $\mathrm{mm}$

$D_{v, i} \quad$ sampled vertical diameter, $\mathrm{mm}$

GOx gaseous oxygen

This is an Open Access article distributed under the terms of the Creative Commons Attribution-Noncommercial License 3.0, which permits unrestricted use, distribution, and reproduction in any noncommercial medium, provided the original work is properly cited. 
$G_{\text {ox }} \quad$ oxidizer mass flux, $\mathrm{kg} / \mathrm{m}^{2} / \mathrm{s}$

$I_{s} \quad$ gravimetric specific impulse, $\mathrm{s}$

$L_{p} \quad$ length of fuel grain, $\mathrm{mm}$

$M \quad$ fuel mass, $\mathrm{g}$

$\dot{m}_{f} \quad$ fuel mass flow rate, $\mathrm{g} / \mathrm{s}$

$\dot{m}_{\text {ox }}$ oxidizer mass flow rate, $\mathrm{g} / \mathrm{s}$

$n \quad$ time exponent in Eq. (1)

$\mathrm{O} / \mathrm{F} \quad$ Oxidizer-to-Fuel ratio

$p$ pressure, bar

$p_{c} \quad$ chamber pressure, bar

$r_{f} \quad$ regression rate, $\mathrm{mm} / \mathrm{s}$

$r_{f, i} \quad$ sampled regression rate, $\mathrm{mm} / \mathrm{s}$

$R^{2} \quad$ correlation index

$t$ time, $\mathrm{s}$

$t_{b} \quad$ burning time, $\mathrm{s}$

\section{Greek Symbols}

$\Delta \quad$ Difference

$\mu \mathrm{Al}$ micro-Aluminum

$\rho_{f} \quad$ solid fuel density, $\mathrm{g} / \mathrm{cm}^{3}$

\section{Abbreviations}

2D two-dimensional

CCP Condensed Combustion Products

CEA Chemical Equilibrium with Applications

DOA DiOctyl-Adipate

fps frames per second

HTPB Hydroxyl-Terminated PolyButadiene

IPDI IsoPhorone Di-Isocyanate

MB Mass Balance

Nlpm Normal-liters per minute

RANS Reynolds-Averaged Navier-Stokes

SPLab Space Propulsion Laboratory

TOT Thickness Over Time

\section{INTRODUCTION}

In the framework of a renewed international interest in hybrid propulsion (see, for example, the current FP7 program promoted by the European Community), SPLab of Politecnico di Milano has been working on a global approach aiming at 
investigating a new generation of innovative fuels for hybrid rockets. Although hybrid propulsion appears, among the thermochemical devices, a very attractive option for both launchers and in-space systems, difficulties are met in developing large-scale hybrid rocket engines. However, some recent advances (such as the implementation of easily liquefiable fuels and/or the addition of high-energy ingredients) seem to suggest possible breakthroughs in the near future. For the time being, the specific objective of propulsive industries is to design, build, and test a technological demonstrator. In this respect, the first task is to experimentally identify a solid fuel formulation featuring large enough regression rates (5-7 mm/s depending on the planned mission) as well as a suitable set of general properties (regarding performance, combustion efficiency and stability, mechanical properties, handling safety, cost, environmental respect, commercial availability, chemical compatibility, etc.).

In general, the development of novel solid fuel formulations aims at increasing the propulsion performance (specific impulse and regression rate) as well as reducing energy losses (due to combustion inefficiency and two-phase flow). At the same time, the challenge for better performing hybrid solid fuels has to account also for satisfactory mechanical properties. A research roadmap has to deliver materials with interesting combustion features as well as mechanical behavior assuring integrity of the solid fuel grain under the operating loads expected for a given propulsive mission. In this framework, SPLab has developed a series of proprietary techniques to evaluate, on a relative grading, the quasi-steady ballistics of solid fuels, including regression rates, while visualizing at the same time their flame structure. Contributions by SPLab in several technical areas are reported in recent publications by this research group [1-13] and also presentations made at the Perseus Project [14-17].

Two hybrid burners are currently in use at SPLab: a 2D radial setup suitable for time-resolved quasi-steady ballistics and a 2D slab setup suitable for boundary layer analyses. After a quick description of the two rigs, representative combustion results are shown for both burners. Companion numerical, thermochemical, and mechanical investigations are illustrated to improve solid fuel mastering for hybrid propulsion. In this paper, the commonly used HTPB polymer was taken as nonmetallized baseline and widely characterized at laboratory level in order to prepare small-scale motor testing with a variety of suitable solid fuels.

\section{TWO-DIMENSIONAL RADIAL MICROBURNER}

Solid-fuel regression rate is the main parameter to understand and predict hybrid rocket engine performance. Early tests on hybrid propulsion used average values of regression rate based on mass (or grain geometry) measurements be- 


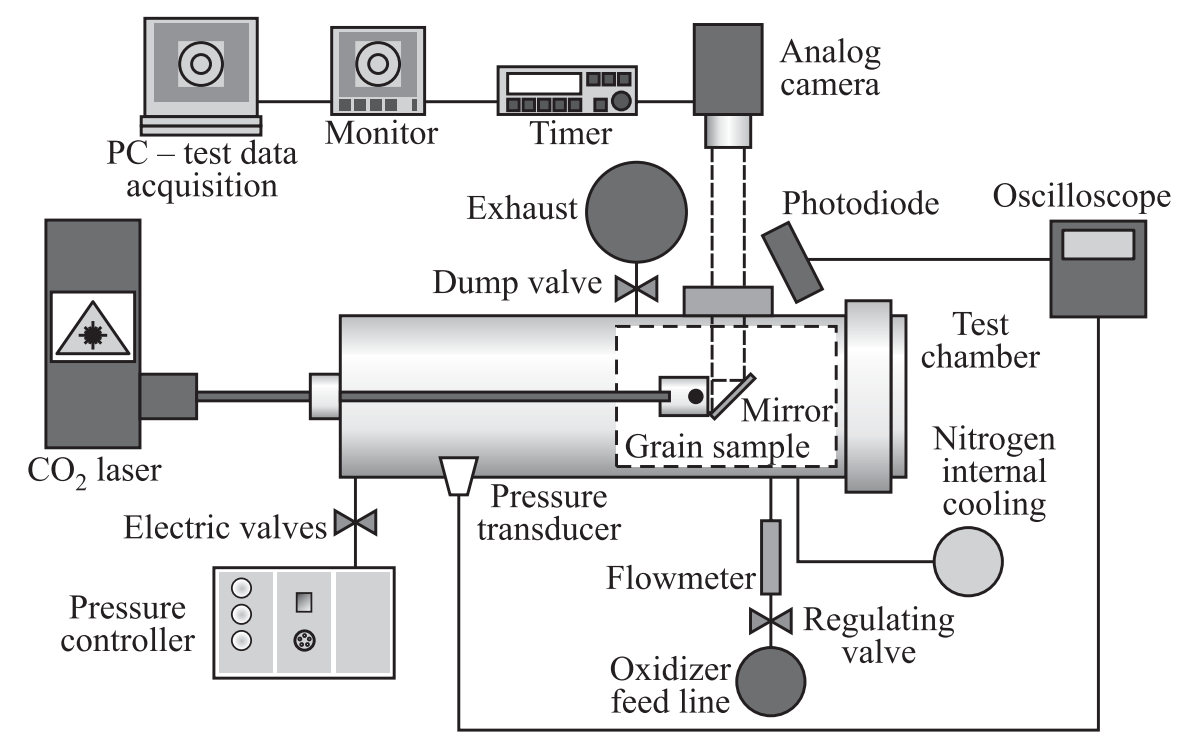

Figure 1 SPLab 2D radial hybrid burner rig (overall view)

fore and after motor firing [18]. Similarly, average information can be achieved by methods exploiting bulk mode frequency [19]. Local values of instantaneous regression rates can be measured, to different degrees of accuracy, by various techniques such as variable electric resistances embedded in the solid fuel grain (low cost, good accuracy, intrusive), ultrasound methods (reliable, nonintrusive, high developing costs), and microwaves (high cost and complex). Techniques based on the visualization of the gasifying surface of the solid fuel grain offer the advantage of a direct measurement of the regression rate [20]. In particular, real-time X-ray radiography [21] offers good accuracy and the possibility of directly measuring regression rates in both space and time; nevertheless, this technique is characterized by high instrument and operating costs. The simple SPLab 2D radial burner enables a continuous tracking of the solid fuel gasifying surface during test at the sample head-end. Therefore, for the visualized section, time-resolved regression rate can be achieved with a simple and low-cost experimental setup.

A 2D radial microburner was designed in order to enable relative ballistic grading of different fuel formulations, as shown in Fig. 1. The main observable of interest was the regression rate of the cylindrical single perforation solid fuel grain. Measurement was performed by a visual technique tracking the gasifying surface of the fuel grain during combustion. Oxidizer mass flow rate and chamber pressure could be regulated independently, thus allowing different test conditions 
to be easily explored. Likewise, different gaseous oxidizers were easily tested by connecting different cylinders to the oxidizer feed line.

The combustion chamber was a stainless steel cylinder housing the injector head and optical accesses for test visualization. The fuel sample head-end was monitored by a 45 degree mirror. Oxidizer was injected through eight holes realized in the internal surface of the sample holder. This feature allowed both axial and swirled oxidizer flowing over the tested fuel surface. The oxidizer was injected by a primary feed line enabling measurement and manual control of the mass flowing through the central port and taking part in the combustion process. Oxidizer flow was measured by a mass flowmeter and regulated by a needle valve. A secondary feed line enabled a nitrogen flow to cool the chamber walls and prevent soot deposition hindering the burning process visualization. A switch allowed using the secondary flow also as a purge to stop combustion.

A dump pipeline connected the combustion chamber to servovalves granting a controlled pressure level during combustion. Servoactuators were characterized by a response time of 4 to $16 \mathrm{~ms}$, and were driven by a regulator receiving signals from a piezoresistive pressure transducer (pressure range up to 70 bar and maximum error $0.1 \%$ full scale) placed in the combustion chamber. The instantaneous pressure and photodiode signals were eventually sent to an oscilloscope, thus enabling detailed test analyses.

Ignition was achieved by a pyrotechnic primer charge, inserted in the central port of the sample head-end and in turn ignited by a laser beam. The overall combustion process was recorded by a $25 \mathrm{fps}$ analog camera. The videosignal, after passing through a timing device, was digitalized by a computer where all raw data (video, pressure transducer, and photodiode signals) were collected and stored.

\subsection{Time-Resolved Characterization of Solid Fuel Burning}

For each test, a reference ignition time $\left(t_{0}=0\right)$ was set as the instant at which the primer charge began to burn (sharp pressure increase) and in turn ignited the solid fuel sample under examination. After ignition, to avoid the difficulties of the observed transient pressure regime, the investigated measurement range started when the pressure peak was fully damped out, thus allowing a quasisteady pressure regime (Fig. 2).

The 2D-radial burner enabled a complete vision of the sample head-end during test, as shown in Fig. 3. Thanks to this feature, regression rates could be evaluated along different radial directions, therefore achieving a complete characterization of combustion evolution in time at the head-end section.

Images recorded during testing were analyzed by a software enabling measurements of vertical, $D_{v, i}$, and horizontal, $D_{h, i}$, diameters of the sample central port at the head-end. From these values, an average diameter $\left(\bar{D}_{i}\right)$ could 


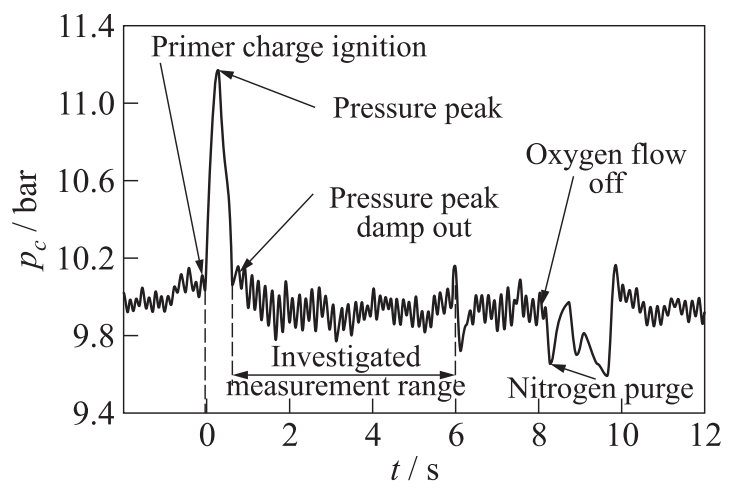

Figure 2 Pressure-time history for a typical burning test run at the 2D radial hybrid burner

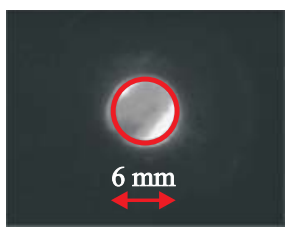

$t=t_{0}$ (ignition)

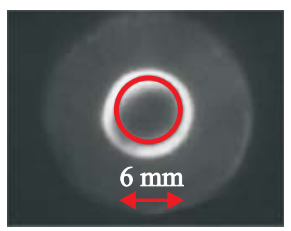

$t=t_{0}+1 \mathrm{~s}$

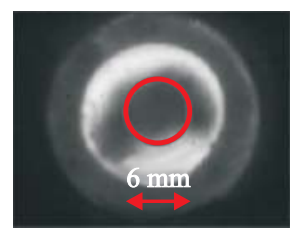

$t=t_{0}+4 \mathrm{~s}$

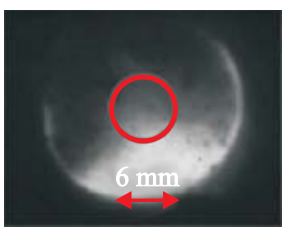

$t=t_{0}+7.5 \mathrm{~s}$

Figure 3 Time history of regressing surface for HTPB under an oxidizer mass flow rate of $70 \mathrm{~kg} /\left(\mathrm{m}^{2} \mathrm{~s}\right)$ of $\mathrm{GOx}$; red circle indicates central port initial diameter $(6 \mathrm{~mm}$ in this test). (Refer DeLuca et al., p. 410.)

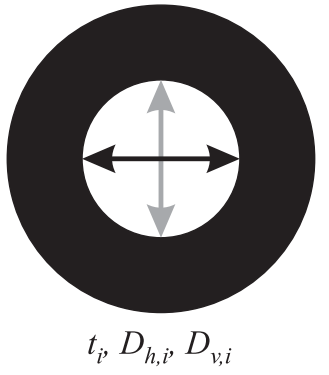

Figure 4 Time-resolved quasi-steady regression rate: definition of mean sampled diameter be defined for each considered frame as shown in Fig. 4:

$$
\bar{D}_{i}=\frac{D_{h, i}+D_{v, i}}{2} .
$$

Different time steps have been investigated for mean diameter evaluations. Based on the instantaneous mean value of the sampled diameter, $\bar{D}_{i}$, the history of central port diameter in time, with respect to its initial value $D_{0}$ at ignition $\left(t_{0}=0\right)$, was defined. The quasi-steady $\left(D-D_{0}\right)$ evolution was then conveniently fitted in time as a power function

$$
D-D_{0}=a t^{n} .
$$

For the investigated operating conditions and implemented optical hardware, a sampling fre- 
quency of $1 \mathrm{~Hz}$ was selected as most suitable in order to grant the tracking of the regressing surface with sufficient accuracy. For the implemented operating conditions, higher sampling rates implied higher errors and, therefore, a lower quality fitting for the diameter time evolution. This was mainly due to possible flame flickering during combustion and exceedingly small web consumption enhancing errors in the gasifying surface identification over short time intervals.

Differentiating the above power law for the central port diameter yields an analytical description of the quasi-steady regression rate time dependence as

$$
r_{f}(t)=\frac{1}{2} \frac{d\left(D-D_{0}\right)}{d t}=\frac{1}{2} a n t^{n-1} .
$$

Now, taking into account the known constant value of the oxidizer mass flow rate and the regression rate of Eq. (3), all of the other instantaneous parameters of interest can be evaluated based on the central port diameter evolution of Eq. (2). In particular, for the oxidizer mass flux, fuel mass flow rate, and oxidizer-to-fuel ratio, one respectively finds:

$$
\begin{aligned}
G_{\mathrm{ox}}(t) & =\frac{\dot{m}_{\mathrm{ox}}}{\pi D^{2} / 4}=\frac{\dot{m}_{\mathrm{ox}}}{\pi\left(D_{0}+a t^{n}\right)^{2} / 4} ; \\
\dot{m}_{f}(t) & =\rho_{f} A_{f}(t) r_{f}(t)=\rho_{f} \pi D L_{p} r_{f}(t)=\rho_{f} \pi\left(D_{0}+a t^{n}\right) L_{p} r_{f}(t) ; \\
\mathrm{O} / \mathrm{F}(t) & =\frac{\dot{m}_{\mathrm{ox}}}{\dot{m}_{f}}=\frac{\dot{m}_{\mathrm{ox}}}{\rho_{f} \pi D L_{p} r_{f}(t)}=\frac{\dot{\mathrm{o}}_{f}}{\rho_{f} \pi\left(D_{0}+a t^{n}\right) L_{p} r_{f}(t)} .
\end{aligned}
$$

Alternatively, the average regression rate over each sampled time interval $t_{i+1}-t$ can also be evaluated directly as a thickness over time (TOT) ratio of sampled diameter difference over sampled time difference during combustion:

$$
\bar{r}_{f, i+1 / 2}=\frac{1}{2} \frac{\bar{D}_{i+1}-\bar{D}_{i}}{t_{i+1}-t_{i}} .
$$

This technique, often used in the literature, is, however, intrinsically subjected to larger errors since based on raw data handling prior to smoothing.

\subsection{Representative Results of Time-Resolved Solid Fuel Burning}

Several tests for HTPB fuel burning in GOx were investigated to assess the quality of the proposed technique. Fuel was prepared starting from HTPB R45 resin cured by IPDI, using DOA as plasticizer and Dibutil Tin Diacetate as curing catalyst $[8,11]$. A degas cycle of the fuel formulation before molding of the samples grants realization of strands with high quality and porosity lower than $1 \%[13]$. Runs were conducted under 70 Nlpm oxidizer volumetric flow rate 


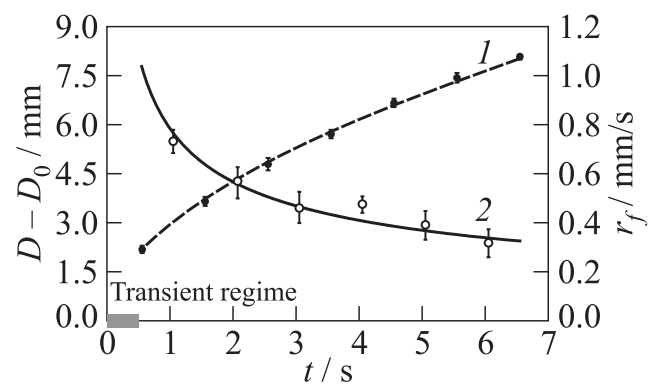

Figure 5 Instantaneous $D-D_{0}\left(1-D-D_{0}=(2.948 \pm 0.030) t^{0.532 \pm 0.008}, R^{2}=0.999\right)$ and regression rate $\left(2-r_{f}=0.784 t^{-0.468}\right)$ vs. time. HTPB burning under $70 \mathrm{Nlpm}$ GOx and 10-bar chamber pressure (Test No.01). For the regression rate, the analytical expression is given by Eq. (2) while the experimental points are evaluated by the TOT finite difference scheme of Eq. (4)

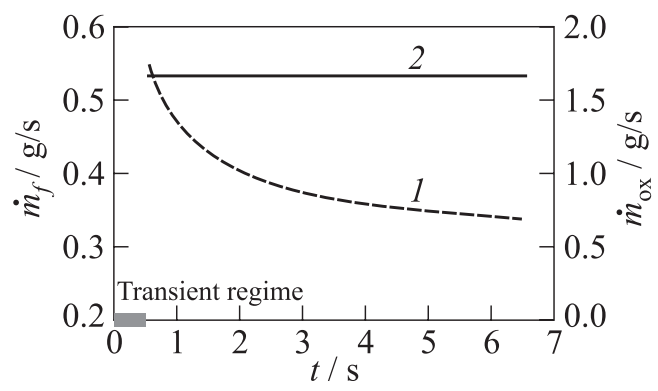

Figure 6 Instantaneous fuel $\left(1-\dot{m}_{f}=(0.464 \pm 0.001) t^{0.183 \pm 0.001}, R^{2}=0.985\right)$ and oxidizer $\left(2-\dot{m}_{\mathrm{ox}}=1.665 \pm 0.041\right)$ mass flow rates vs. time. HTPB burning under 70 Nlpm GOx and 10-bar chamber pressure (Test No.01). Oxidizer mass flow rate error defined by flowmeter measurement during combustion within $\pm 2.5 \%$ of the mean value

and 10-bar chamber pressure. The investigated solid fuel grain geometry was characterized by an initial central port diameter of $4 \mathrm{~mm}$. The results obtained for a typical test are summarized in Fig. 5 (diameter and regression rate vs. time), Fig. 6 (fuel and oxidizer mass flow rates vs. time), Fig. 7 (oxidizer mass flux and oxidizer/fuel ratio vs. time), and Fig. 8 (regression rate vs. oxidizer mass flux).

Figure 5 shows how the central port diameter $D(t)$ and regression rate $r_{f}(t)$ change with time during quasi-steady burning: one can immediately observe that $D(t)$ increases with time due to fuel consumption, while $r_{f}(t)$ decreases. Figure 6 shows how the fuel mass flow rate $\dot{m}_{f}$ and oxidizer mass flow rate $\dot{m}_{\text {ox }}$ 


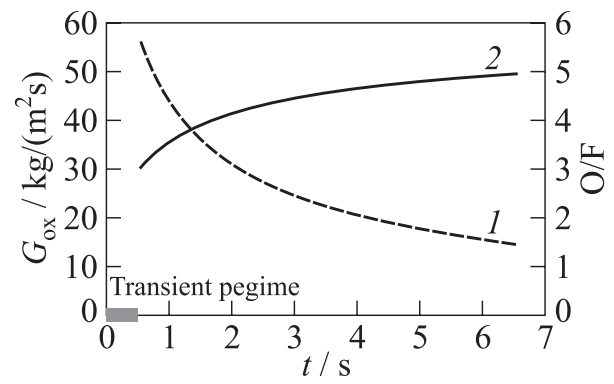

Figure 7 Instantaneous oxidizer mass flux $\left(1-G_{\mathrm{ox}}=(42.836 \pm 0.105)\right.$ $\left.\times t^{0.542 \pm 0.002}, R^{2}=0.991\right)$ and $\mathrm{O} / \mathrm{F}\left(2-\mathrm{O} / \mathrm{F}=(3.588 \pm 0.004) t^{0.183 \pm 0.002}\right.$, $\left.R^{2}=0.985\right)$ vs. time. HTPB burning under 70 Nlpm GOx and 10-bar chamber pressure (Test No.01)

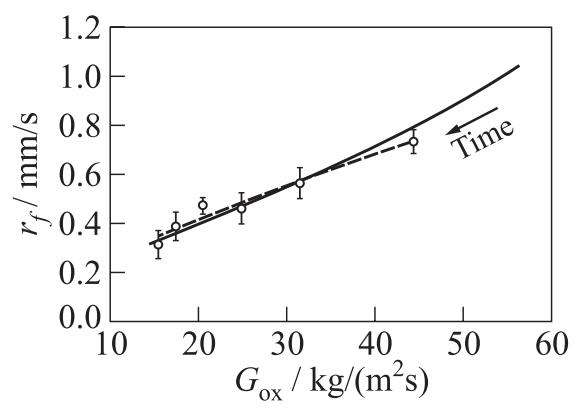

Figure 8 Analytical (solid line $\left.-r_{f, \text { anal }}=(0.0351 \pm 0.0003) G_{\mathrm{ox}}^{0.816 \pm 0.003}, R^{2}=0.994\right)$ and experimental (dashed line $\left.-r_{f, \text { ТОт }}=(0.050 \pm 0.013) G_{\mathrm{ox}}^{0.717 \pm 0.082}, R^{2}=0.937\right)$ regression rates vs. oxidizer mass flux. HTPB burning under 70 Nlpm GOx and 10-bar chamber pressure (Test No. 01). The transient regime extending from the initial oxidizer mass flow rate of $130 \mathrm{~kg} /\left(\mathrm{m}^{2} \mathrm{~s}\right)$ to the first sampled diameter at about $55 \mathrm{~kg} /\left(\mathrm{m}^{2} \mathrm{~s}\right)$ is not reported to better show analytical and TOT results over the investigated measurement range

change with time during quasi-steady burning: $\dot{m}_{f}$ decreases with time due to the combined effect of fuel consumption and $r_{f}(t)$ decrease, while $\dot{m}_{\text {ox }}$ remains constant. Figure 7 shows how the oxidizer mass flux $G_{\text {ox }}$ and oxidizer/fuel ratio $\mathrm{O} / \mathrm{F}$ change with time during quasi-steady burning: $D(t)$ increase and constant $\dot{m}_{\text {ox }}$ induce a $G_{\text {ox }}(t)$ decrease, while $\mathrm{O} / \mathrm{F}=\dot{m}_{\mathrm{ox}} / \dot{m}_{f}$ increases. Based on Eq. (1) for $D(t)$ and Eq. (2) for $r_{f}(t)$, all ballistic parameters can, therefore, be expressed in analytical closed forms. The exact expressions are reported for $\dot{m}_{f}$ in Fig. 6, and for $G_{\text {ox }}$ and $\mathrm{O} / \mathrm{F}$ in Fig. 7. 
A typical trend of regression rate vs. oxidizer mass flow rate is shown in Fig. 8, contrasting the continuous (solid line) regression rates $r_{f \text {, anal }}$ as evaluated by the analytical expression of Eq. (2) to the discrete (dashed line) regression

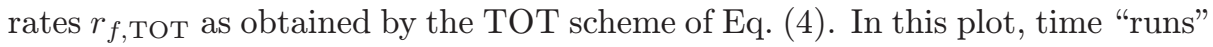
from right to left $\left(G_{\text {ox }}\right.$ decreasing with time) as shown in Fig. 7.

A simple but important remark is that, due to the ignition transient, a certain fraction of the initial portion of the test with large $G_{\mathrm{ox}}$ value is quickly lost, leading most of the burning to take place under much reduced $G_{\mathrm{ox}}$, as can be seen in Fig. 8 where initial oxidizer mass flow rate is around $55 \mathrm{~kg} /\left(\mathrm{m}^{2} \mathrm{~s}\right)$ instead of the starting value of $130 \mathrm{~kg} /\left(\mathrm{m}^{2} \mathrm{~s}\right)$. This effect to some degree pollutes the quality of the experimental data based on the initial or average $G_{\text {ox }}$ values, often reported in the literature, and partly accounts for the observed large data scattering.

Table 1 Regression rate vs. $G_{\text {ox }}$ for three tests of HTPB burning in GOx. Operating conditions: 70 Nlpm GOx and 10-bar chamber pressure

\begin{tabular}{llc}
\hline \multirow{2}{*}{ Test } & \multicolumn{2}{c}{ Regression rate vs. oxidizer mass flow rate } \\
\cline { 2 - 3 } & \multicolumn{1}{c}{ Analytical } & Data Fitting $\left(R^{2}\right)$ \\
\hline No. 01 & $r_{f}=(0.0351 \pm 0.0003) G_{\mathrm{ox}}^{0.816 \pm 0.003}$ & 0.994 \\
No. 02 & $r_{f}=(0.0368 \pm 0.0004) G_{\mathrm{ox}}^{0.795 \pm 0.003}$ & 0.993 \\
No. 03 & $r_{f}=(0.0353 \pm 0.0003) G_{\mathrm{ox}}^{0.813 \pm 0.003}$ & 0.992 \\
\hline & Experimental (TOT finite difference) & Data fitting $\left(R^{2}\right)$ \\
\hline No. 01 & $r_{f}=(0.050 \pm 0.013) G_{\mathrm{ox}}^{0.710 \pm 0.082}$ & 0.937 \\
No. 02 & $r_{f}=(0.031 \pm 0.021) G_{\mathrm{ox}}^{0.836 \pm 0.204}$ & 0.853 \\
No. 03 & $r_{f}=(0.054 \pm 0.014) G_{\mathrm{ox}}^{0.687 \pm 0.083}$ & 0.931 \\
\hline *Test measurement interval limited to 5 s instead of $6 \mathrm{~s}$.
\end{tabular}

${ }^{*}$ Test measurement interval limited to $5 \mathrm{~s}$ instead of $6 \mathrm{~s}$.

A wider comparison between analytical and experimental (i.e., TOT finite difference) data is reported in Table 1. Analyses of the obtained regression rate data as a function of the oxidizer mass flow rate point out a power-law correlation with exponent around 0.8 , just the theoretical value identified by Marxman for boundary layer diffusion-limited combustion $[22,23]$. On the contrary, a straightforward fitting of the experimental regression rate data (TOT method) exhibits the typical exponent of approximately 0.71 found in the literature [19-24]; in addition the quality of the data fitting in terms of $R^{2}$ is slightly reduced. For the explored operating conditions, the implemented time-resolved videotechnique points out the superiority, in data handling, of tracking in time the diameter history rather than directly the regression rate. This is proved by the data scattering of discrete $r_{f}$ in Fig. 8 and the associated low fitting quality in Table 1. 


\section{TWO-DIMENSIONAL SLAB BURNER AND NUMERICAL SIMULATION}

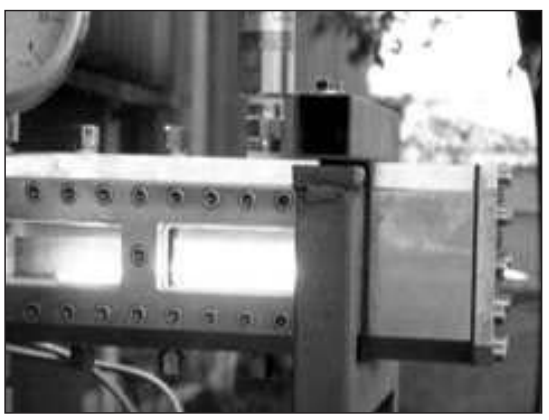

Figure 9 SPLab 2D slab hybrid burner rig during a combustion test
A 2D slab burner was specifically designed at SPLab to investigate the details of hybrid flame structure. This experimental facility (Fig. 9) includes a windowed, slab-geometry combustion chamber, an ignition system, and convenient devices for feeding, control, and extinction. The burner is based on a $2 \mathrm{D}$ slab chamber, useful to investigate the boundary layer and its flame structure, metal powder behavior, and the general development of the combustion process.

A pyrotechnic charge is used for fuel ignition. The combustion chamber is supplied with different geometry sample holders, allowing tests with different sample geometries; in particular, single and double slab configurations are available. Moreover, chamber height can be varied; thus, the distance between the fuel slabs (or between slab and wall in single slab configuration) can be adjusted.

The oxygen inlet system includes a calibrated nozzle and a differential manometer for oxygen mass flow measurement. Rapid flame extinction is ensured by a nitrogen inlet system. A check valve prevents oxygen and nitrogen mixing. A pressure transducer allows measuring the pressure trace. Postprocessing leads to burning time determination and average regression rate measurement.

The fuel mass flow rate can be expressed as the ratio between the fuel mass consumed during combustion and the burning time, for which the initial fuel sample mass before combustion and the corresponding final mass after the firing test were measured. According to this mass balance (MB) method, the average regression rate can be easily obtained as

$$
r_{f}=\frac{\Delta m}{A_{f} \rho_{f} t_{b}} .
$$

High-speed camera visualization allowed measuring the height of the hybrid flame in the boundary layer. The camera was placed near the window of the chamber and was settled in order to visualize the whole grain. The focal plane of the camera was placed about $200 \mathrm{~cm}$ from the sample, perpendicular to the windows. The vertical height was the same of the sample. The visualization could be performed at 250-500 fps without loosing too much in temporal details while the image size could be set up to $1024 \times 512$ (horizontal strip). 


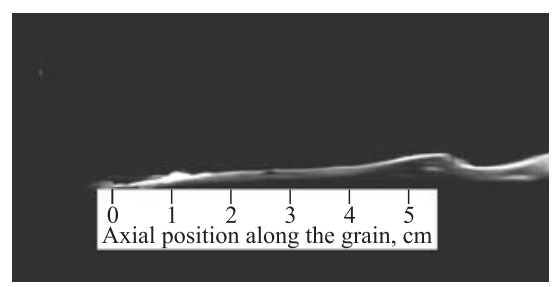

Figure 10 Example of frame taken from pure HTPB firing test visualization. Oxygen inlet velocity $4 \mathrm{~m} / \mathrm{s}$; chamber pressure $1.3 \mathrm{bar}$
Before the combustion was performed, a ruler was placed in the combustion chamber and a short recording was performed in order to calibrate the system. The object dimension was measured in pixels with an open source software for picture manipulation, and then the value was converted to meters. The calibration process was repeated for each firing test for obtaining a correspondence between pixel and real dimension. Results are reported for tests with inlet velocity of 4 and $6 \mathrm{~m} / \mathrm{s}$. Oxygen inlet velocity was measured using a calibrated nozzle.

A selection of 20 frames was made; a typical frame is shown in Fig. 10 for the inlet velocity of $4 \mathrm{~m} / \mathrm{s}$. The time interval between the selected frame is constant, set to $6 \mathrm{~s}$. For each frame, the flame height was measured at five different equally spaced sections along the grain as shown in Fig. 10. The grain was $5 \mathrm{~cm}$ long and the sections were $1 \mathrm{~cm}$ spaced. The average value of the flame height was measured and the uncertainty was calculated, with Student's t-method, for each section along the grain for a population of twenty measurements. The uncertainty was computed to consider the error that the operator could introduce during the measurement process of the flame height in pixels. The experimental flame height was computed as the point of maximum luminosity in the flame.

\subsection{Numerical Code}

SPLab is involved in the development of HybridFOAM, a numerical code based on the OpenFOAM framework library [25], entirely programmed in $\mathrm{C}++$. The code is implemented in order to simulate the unsteady, turbulent, and reacting boundary layer with blowing effects, radiation, and chemical kinetics, characterizing the hybrid rocket engine combustion processes. Two separate domains, for the reactive gas mixture and the solid fuel grain, are implemented to consider the interaction between the two phases, bringing to the calculation of the regression rate and the inlet fuel vapors velocity.

The code deals with Navier-Stokes equations coupled with additional transport equations for combusting species, solved with RANS approach in the gaseous region; the equations are closed with $k-\varepsilon$ turbulence model and well stirred reactor model [26]. The influence of radiation on the grain surface temperature and, hence, on the regression rate is taken into account implementing a model based on the expansion of radiation intensity in an orthogonal series of spherical harmonics [27]. The energy equation, to calculate the temperature profile in 


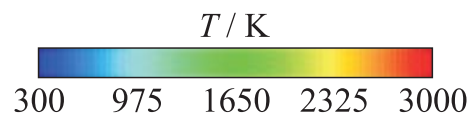

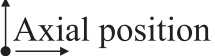

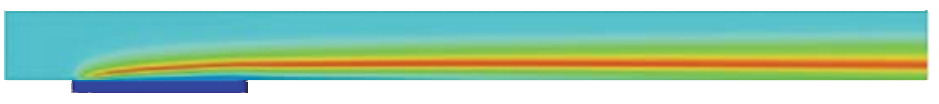

Figure 11 Temperature for inlet velocity of $4 \mathrm{~m} / \mathrm{s}$ and chamber pressure of 1.3 bar. (Refer DeLuca et al., p. 417.)

the grain, is solved in the solid region. The solid fuel regression rate, including transient phenomena and spatial variations, is evaluated through the coupled gas-solid interfacial boundary condition. The fuel vapors inlet velocity in the gaseous region is updated each time step by writing the continuity equation at the interface; the regression rate is computed from the HTPB fuel pyrolysis. The coupling between the gas phase and the heat conduction in the solid fuel allows the solution to include any effect coming from the thermal lag of the condensed phase.

A formulation with HTPB burning in GOx was chosen for validation. A fourreaction model for combustion of butadiene, considered as the major gaseous constituent coming from HTPB pyrolysis [28], was used for reactions occurring in oxygen atmosphere. A temperature distribution is shown in Fig. 11. The combustion in hybrid rocket motors leads to the formation of a diffusive flame placed in the fluid dynamic boundary layer as shown in Fig. 11. Near the leading edge of the fuel slab, the boundary layer is very thin and has relatively large velocity and temperature gradients, which result in high shear stress and convective heat flux. The boundary layer grows with the axial direction causing the velocity and temperature gradients and, therefore, the convective flux to decrease. At the same time, the local mass flux increases in the downstream direction due to the upstream fuel injection and this effect tends to increase the convective heating.

\subsection{Comparing Numerical Predictions and Experimental Data}

The $2 \mathrm{D}$ slab geometry was selected for the first validation test of the numerical code. The experimental value of the flame height was compared with the numerical results. The numerical flame height was estimated as the distance from the grain surface where the temperature profile reaches the maximum value. The experimental flame height was taken where the flame luminosity reached its highest intensity. Figures $12 a$ and $12 b$ for, respectively, 4 and $6 \mathrm{~m} / \mathrm{s}$ of inlet velocity show a good agreement between experimental and numerical data.

Another comparison was carried out in terms of experimental vs. numerical regression rates. The average regression rate values obtained in the $2 \mathrm{D}$ slab 


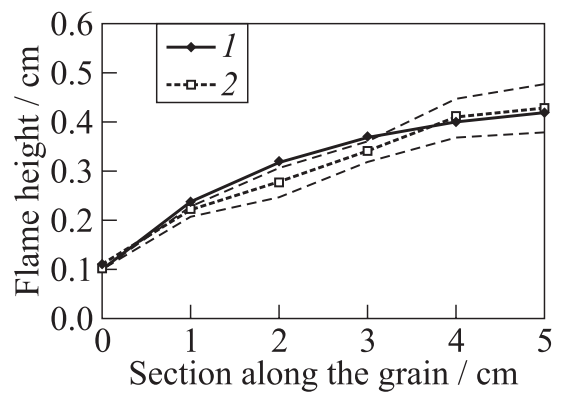

(a)

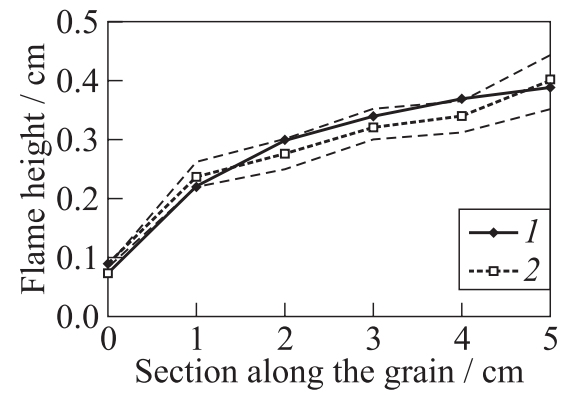

(b)

Figure 12 Comparison between numerical (1) and experimental (2) flame height for inlet velocity of $4(a)$ and $6 \mathrm{~m} / \mathrm{s}(b)$ and chamber pressure of 1.3 bar. Dashed lines represent the uncertainty interval of the experimental flame height

burner are shown in Fig. 13. A comparison with some experimental data from the open literature is also shown. Literature data are obtained with firing tests in slab motors (see for details $[29,30]$ ). SPLab results are very similar to the data from Strand et al. [29], and slightly different from those by Chiaverini et al. [30].

The regression rate varies not only with time but also along the grain surface, being linked to the grain surface temperature according to the Arrhenius law $[30,31]$. The reported numerical results of regression rate are the averaged values in time and space; this choice was made to allow the comparison with the experimental results.

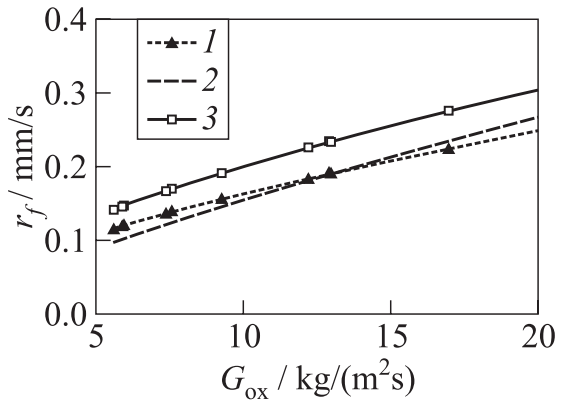

Figure 13 Regression rate vs. oxidizer mass flux for pure HTPB in GOx. Combustion chamber pressure 1.3 bar. Comparison between SPLab data (1) and literature data: $2-[29]$ and $3-[30]$

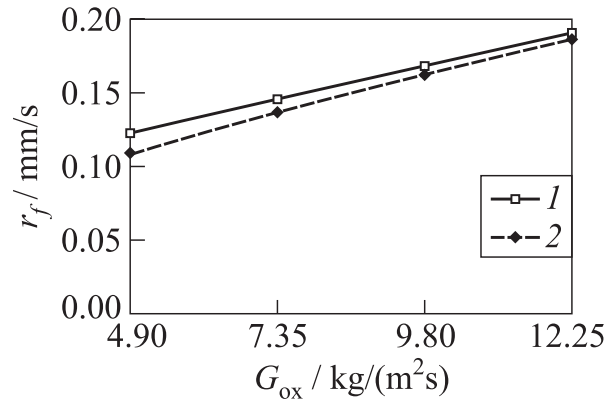

Figure 14 Numerical (1) regression rate compared to experimental (2) data from SPLab 2D slab burner. Chamber pressure 1.3 bar 
The increase in inlet velocity yields an increase in the regression rate due to flame height decrease and grain-surface temperature increase. A direct comparison between numerical and experimental values of regression rate is reported in Fig. 14. A good agreement is seen between numerical and experimental results.

\section{USING THERMOCHEMISTRY FOR HYBRID FUEL CHARACTERIZATION}

Even though thermochemistry cannot come up with the prediction of regression rates, it may be used to drive fuel developments towards more efficient formulations. Usually, this search can address towards fuels with higher theoretical specific impulse and reduced content of solid residues in the combustion products, thus reducing the two-phase flow losses. The method of investigation relies on the minimization of Gibbs free energy and on the identification of the final (equilibrium) chemical composition, given the initial reactants and the operating conditions. The outcomes from this method of analysis are the adiabatic flame temperature, specific impulse data, the evolution of combustion products

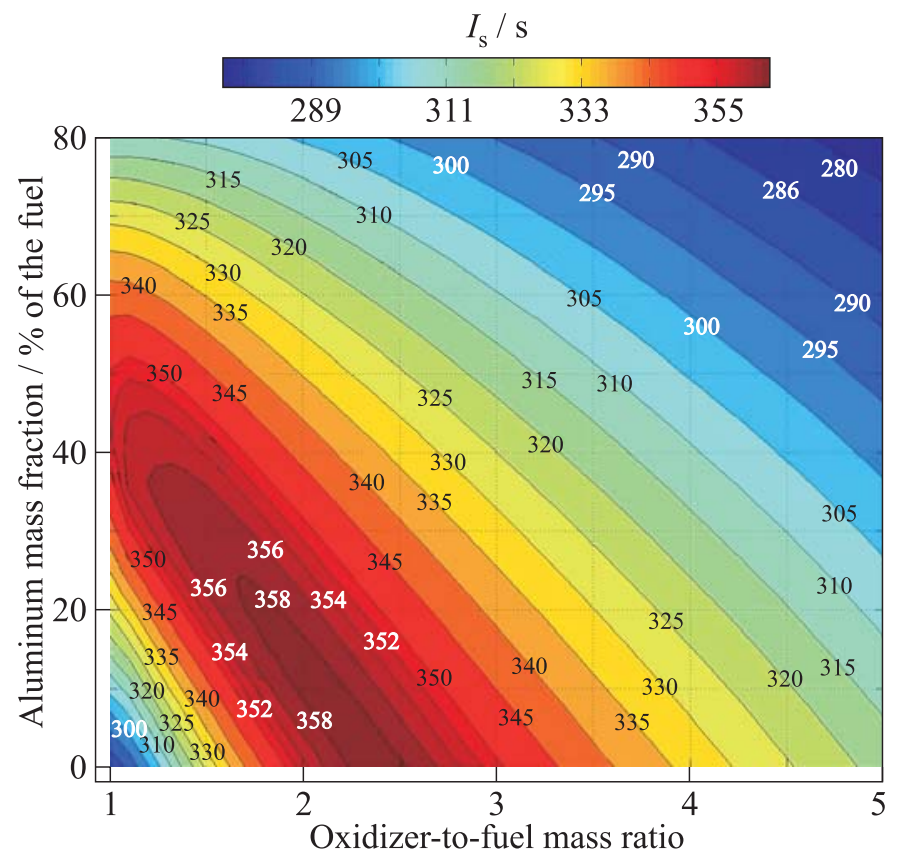

Figure 15 Vacuum specific impulse for HTPB, Al, GOx: shifting equilibrium model. Operating conditions: chamber pressure 70 bar and area ratio $A_{e} / A_{t}=40$. (Refer DeLuca et al., p. 419.) 
through the nozzle expansion, and thermodynamic and transport properties for the mixture $[32,33]$. The first logical step in the frame of SPLab strategy for hybrid propulsion was to evaluate the theoretical rocket motor performance obtained when a new fuel was considered. Iso-level gravimetric specific impulse $\left(I_{\mathrm{S}}\right)$ curves were built to analyze the $I_{\mathrm{S}}$ behavior according to the mixture ratio variation and the energetic material mass fraction; a typical example is shown in Fig. 15. This kind of performance estimation is obtained with the open source CEA code (Chemical Equilibrium with Applications) developed by NASA [34].

An extensive series of formulations are currently under investigation, carrying on a systematic analysis of the performance granted. A variety of fuels (HTPB and paraffins), and energetic additives (metals and their hydrides) oxidized by gaseous or liquid oxygen are considered for equilibrium combustion and nozzle expansion under the assumption of frozen chemistry or local (shifting) equilibrium. Typical results for aluminum and gaseous oxygen are reported in Fig. 15 for shifting equilibrium. As reported in a previous conference paper [9], frozen expansion grants the maximum $I_{\mathrm{s}}$ for relatively large percentage of $\mathrm{Al}$ (with respect to the total amount of fuel in the formulation), while for shifting expansion the maximum $I_{\mathrm{s}}$ is obtained with no Al. These results highlight the importance of aluminum oxide (alumina) phase transition in the combustion products during shifting expansion, due to a phase change from solid to liquid $\mathrm{Al}_{2} \mathrm{O}_{3}$, located where the highest $I_{\mathrm{S}}$ in shifting conditions is obtained. The details of alumina transition can be analyzed in Fig. 16 which reports the phase of the CCP at the exhaust. Liquid aluminum oxide is still present for formulations in the $\mathrm{O} / \mathrm{F}$

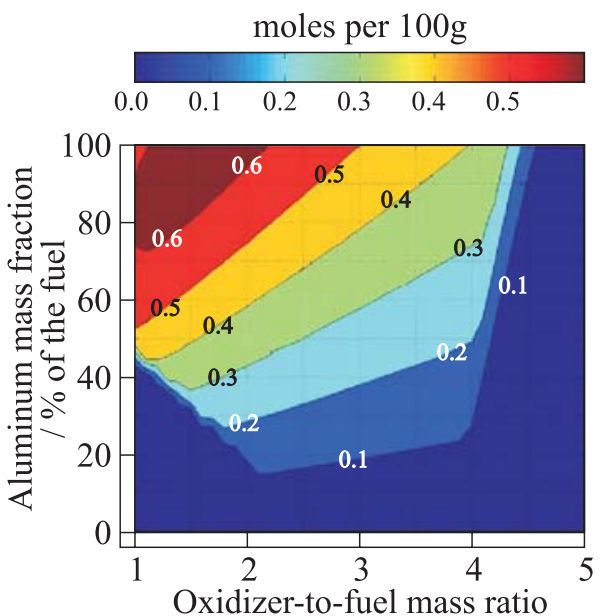

(a)

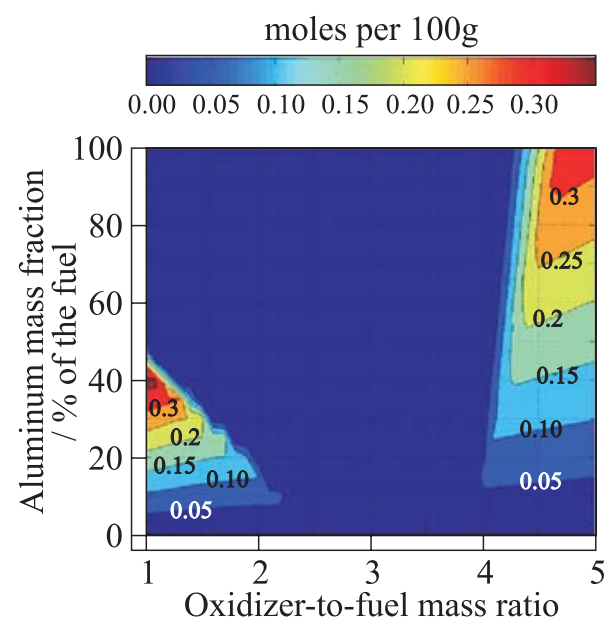

(b)

Figure 16 Exhaust aluminum oxide for HTPB, Al, GOx [9]: (a) liquid alumina; and (b) solid alumina. (Refer DeLuca et al., p. 420.) 
activity at SPLab aims at the mechanical characterization of the formulations that have demonstrated the most promising ballistic features. A series of tensile tests and dynamic mechanical analyses document the elastic modulus, rupture conditions, and the behavior at different strain rates as a function of solid fillers (size and fraction), plasticizers, and curing degree. Ageing activities are currently under development.

The data here document a research activity for the development of novel fuel formulations based on a binder polymer (HTPB, DOA 11\% by mass, IPDI saturation $100 \pm 2 \%$ ) plasticized with a consistent fraction of liquid paraffin. In fact, a current trend for hybrid fuel formulation is the use of paraffin inside the fuel as a promoter of entrainment effect and, thus, bearer of a higher regression rate. The feasibility and stability of highly plasticized HTPB polymers with lowmolecular liquid paraffin is fostered by the statistical-thermodynamic modeling of swelling phenomena, according to the theory of Flory and Huggins, applied to the specific polymer-solvent interaction [35, 36]. Some preliminary curing tests acknowledged the capability of reaching the theoretical value of plasticizer content (paraffin and DOA)

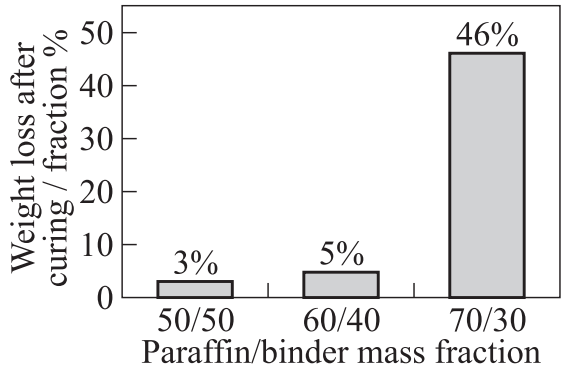

Figure 18 Mixed paraffin/binder polymer: weight loss after curing process

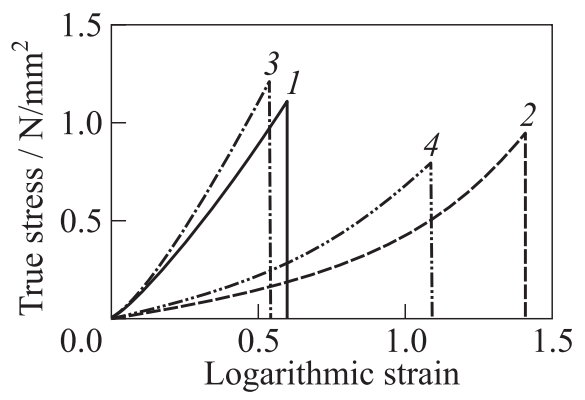

Figure 19 Stress/strain curves for sample tested formulations: 1 - binder (baseline); 2 - paraffin/binder (50/50); 3 - binder/aluminum (90/10); and 4 paraffin/binder/aluminum (40/50/10) that is estimated between $60 \%$ and $70 \%$ of mass fraction and assessed the stability of the final mixture. Figure 18 reports the fraction of mass that a cured sample lost right after the end of the curing process. The mass released by the polymer is in a liquid viscous shape and similar to the original paraffin, specific analysis was not performed though.

Uniaxial tests were performed using dumbbell samples, shaped according to the standard DIN 53504 S3A, and an Instron testing facility (4302 series) on the following formulations [37]:

- pure binder (HTPB based, baseline);

$-50 \%$ binder $+50 \%$ liquid paraffin; 


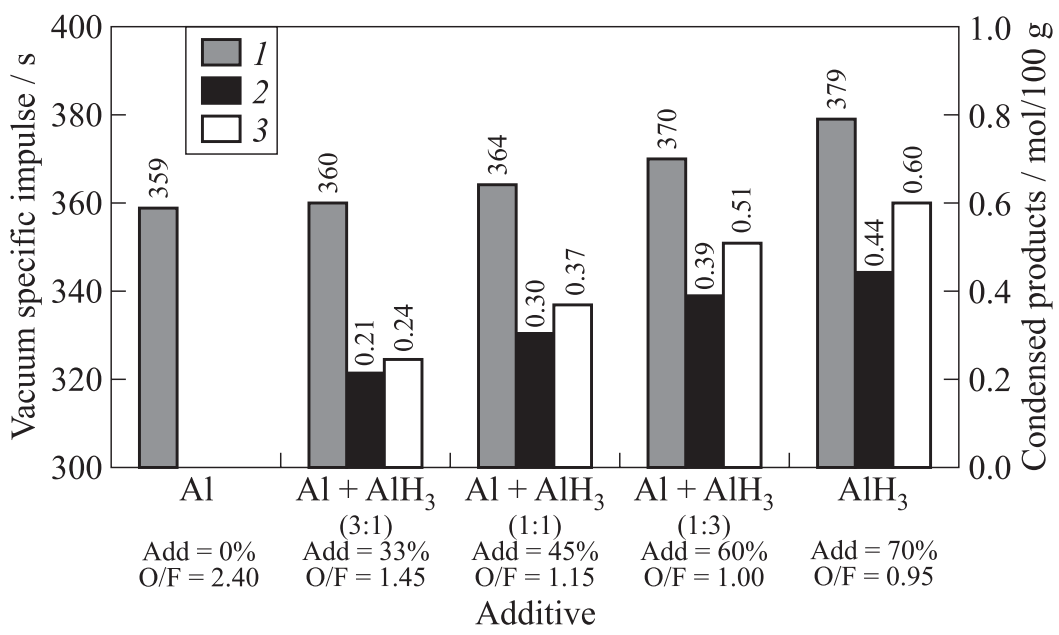

Figure 17 Maximum specific impulse (1) and aluminum oxide content in the exhaust (2 - throat and 3 - exit). Combustion of a $\mathrm{HTPB} /\left(\mathrm{Al}+\mathrm{AlH}_{3}\right)$ fuel in $\mathrm{GOx}$ at 70 bar with expansion ratio of 40

range between 2 and 4 , meaning that the exhaust temperature is still higher than its melting point.

Deeper understanding of CCP can lead to a preliminary estimate of specific impulse losses. In fact, the condensed fraction retains a velocity and thermal lag with respect to the gas when it expands through the supersonic nozzle. Figure 17 represents a theoretical study about the combustion of HTPB filled with mixtures of $\mathrm{Al}$ and $\mathrm{AlH}_{3}$. Partial substitution of $\mathrm{AlH}_{3}$ with micrometric aluminum is investigated looking at the best specific impulse and also the CCP content. It is worth noting that the cases where theoretical $I_{\mathrm{S}}$ is high come along with an increased amount of solid fraction in the exhaust. Although this information is not enough to quantify losses, it represents a useful indication, in conjunction with experimental data on the agglomerate size, to roughly quantify specific impulse losses via empirical formulae [9].

\section{MECHANICAL CHARACTERIZATION OF HYBRID FUELS}

The challenge for more performing hybrid fuels has also to compete with appropriate mechanical properties. Given a specific mission, stiffness and elongation of the fuel should ensure the integrity of the grain under the operating loads. Moreover, the use of additives such as hydrides may lead to compatibility issues and undesired ageing that may prevent the formulation from the use. Current 


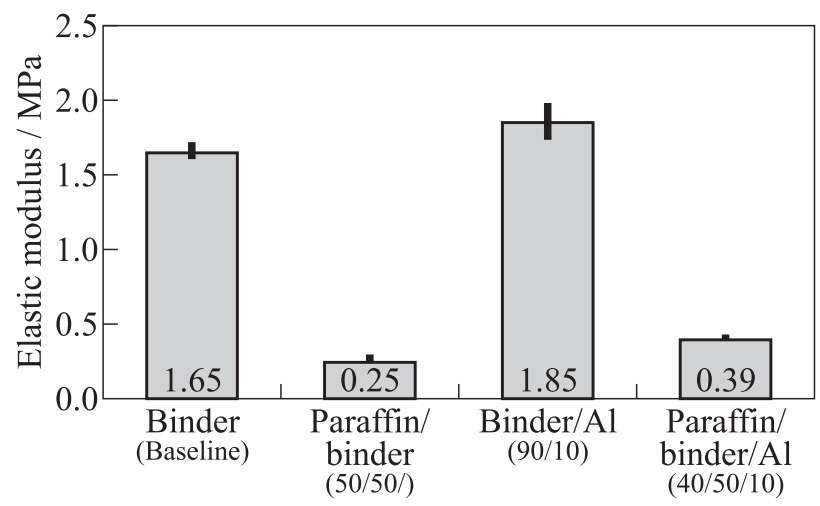

Figure 20 Elastic modulus of mixed binder/paraffin formulations, unfilled and filled with $10 \%$ aluminum. Crosshead speed $50 \mathrm{~mm} / \mathrm{min}$. Upper bar: standard deviation of experimental data

- binder $+10 \% \mu \mathrm{Al}$ filler (30-micron size, spherical); and

- $50 \%$ binder $+40 \%$ liquid paraffin $+10 \% \mu \mathrm{Al}$ filler.

Some relevant curves are plotted in Fig. 19 while the comparison of the elastic tangent modulus defined according to ASTM 111 is in Fig. 20, both for the same crosshead speed of $50 \mathrm{~mm} / \mathrm{min}$.

The mixed formulations made of HTPB binder and paraffin demonstrate the softening effect due to the addition of the plasticizer and, for this reason, the elastic modulus is reduced accordingly for both aluminized and nonaluminized compounds. In conjunction with the elastic modulus, a limited decrease of the maximum stress is also visible, along with an increment of the breakup strain which is more than doubled. It is worth noting that the presence of aluminum inside a mixed formulation results in penalized rupture performance for both strain and stress.

\section{CONCLUDING REMARKS AND FUTURE WORK}

A time-resolved technique capable of following the quasi-steady ballistics of solid fuels in cylindrical grains with a central perforation was designed and validated for pure HTPB burning in GOx. Due to the inherent possibility of tracking diameter evolution along different radial directions, the proposed videotechnique also permits evaluating differences along specific directions (for example, horizontal and vertical diameters) with respect to the corresponding average trend. This enables the definition of an anisotropy index of the combustion process not possible with other diagnostic techniques. This extension of the proposed technique is currently under way. 
High-speed and high-resolution visualization of the flame structure in the 2D slab burner show a turbulent flame with waves moving along the flame surface. Even for pure HTPB, liquid droplets are occasionally seen to detach from the burning surface and be entrained in the boundary-layer gas flow. Extension of the visualization technique to paraffin burning, where entrainment was shown to be a crucial factor for regression rate increase, is currently under way.

Numerical development of a solver for hybrid slab combustion has come to a good state of advancement. A comparison between predicted and experimental flame heights and regression rates was successfully attained. The validation phase will also be extended to surface and flame temperatures. The development roadmap is now looking at the extension of the solver with a moving mesh to simulate the actual regression rate of the solid fuel grain and the simulation of entraining fuels with droplet release.

Relevant to entraining formulations, the feasibility of highly plasticized paraffin-based formulations was proven and mechanically tested, demonstrating interesting breakup properties. High scattering of data was attained though, due to a sample shape that is not properly tuned for soft fuel formulations. New sample shapes will be readily available in order to enhance testing capabilities.

In general, the proposed time-resolved technique to analyze regression of solid fuels for hybrid propulsion appears promising and is currently being extended to a variety of high-energy solid fuels of interest for hybrid propulsion.

\section{ACKNOWLEDGMENTS}

This work has partially been supported by CNES under order No. 4700024752/ DLA090 and order No.4700028003/DLA094. The authors also wish to thank their colleagues of the Department of Aerospace Engineering of Politecnico di Milano for making available the Instron apparatus used for mechanical testing.

\section{REFERENCES}

1. Bosisio, F., H. Raina, G. Colombo, L. Galfetti, and L. T. DeLuca. 2006. Setting up a hybrid microcombustor. Changes in Aeronautical and Space Systems, Challenges for On-Board Energy. Avignon, France.

2. DeLuca, L. T., L. Galfetti, F. Bosisio, H. Raina, A. Colombo, and G. Colombo. 2006. A hybrid microcombustor for regression rate measurements. 57th Astronautical Congress (International) Proceedings. Valencia, Spain. Paper No. IAC06-C4.2.01.

3. Rossettini, L. L., F. Magistrelli, M. Mantegazza, L. Marini, L. DeCillia, A. Conti, P. Simontacchi, C. Renna, P. Mittino, G. Rapicano, G. Festa, L. T. DeLuca, L. Galfetti, A. Russo Sorge, and C. Carmicino. 2007. Advanced hybrid propellant for a Moon orbiter thruster. 2nd EUCASS. Brussels, Belgium. 
4. Calabro, M., L. T. DeLuca, L. Galfetti, and C. Perut. 2007. Advanced hybrid solid fuels. 58th Astronautical Congress (International) Proceedings. Hyderabad, India. Paper No. IAC-07-C4.2.09.

5. Galfetti, L., L. T. DeLuca, P. Grassi, C. Paravan, V. Luoni, A. Bandera, G. Colombo, L. DeCillia, R. Sempio, and H. Raina. 2008. Combustion behavior investigation of solid fuels using a micro-sized hybrid rocket motor. In: Advancements in Energetic Materials and Chemical Propulsion. Eds. K. K. Kuo, and K. Hori. USA: Begell House. 199-213.

6. Galfetti, L., L. T. DeLuca, F. Maggi, and G. Colombo. 2009. Advances in hybrid propulsion at the Space Propulsion Laboratory of Politecnico di Milano. 20th AIDAA Congress. Milan, Italy.

7. Merotto, L., M. Boiocchi, L. Galfetti, G. Colombo, and L. T. De Luca. 2009. Regression rate measurement of hybrid rocket metallized solid fuels: Influence of oxidizer mass flux and pressure. 20th AIDAA Congress. Milan, Italy.

8. Paravan, C., M. Viscardi, L. T. DeLuca, and L. Prada López. 2009. Anisotropy effects in hybrid fuels burning in a micro-burner. 20th AIDAA Congress. Milan, Italy.

9. Gariani, G., F. Maggi, and L. Galfetti. 2009. Numerical analysis of the specific impulse for hybrid fuel with energetic materials. 20th AIDAA Congress. Milan, Italy.

10. Galfetti, L., L. T. De Luca, F. Maggi, and G. Colombo. 2009. Advances in hybrid propulsion. 3rd EUCASS. Versailles, France.

11. Paravan, C., M. Viscardi, L. T. De Luca, and A. Kazakov. 2009. Regression rates and anisotropy effects in hybrid rockets microburner. 3rd EUCASS. Versailles, France.

12. Gariani, G., F. Maggi, T. Lucchini, T. Faravelli, and L. Galfetti. 2009. 2D numerical simulation of combustion processes in a slab hybrid rocket motor. 3rd EUCASS. Versailles, France.

13. Galfetti, L., L. T. De Luca, C. Paravan, L. Merotto, and M. Boiocchi. 2009. Regression rate and CCPs measurement of metallized solid fuels. 8th ISICP. Cape Town, South Africa.

14. Raina, H., F. Bosisio, L. DeCillia, G. Colombo, L. Galfetti, and L. T. DeLuca. 2007. An hybrid microcombustor for increased regression rates. 2ème Séminaire PERSEUS. Paris, France.

15. Paravan, C., P. E. Frossard, H. Raina, P. Grassi, M. Mantegazza, M. Magistrelli, M. Boiocchi, F. Passera, V. Luoni, and L. DeCillia. 2008. Hybrid propulsion studies at SPLab. 3ème Séminaire PERSEUS. Paris, France.

16. Viscardi, M., C. Paravan, L. Merotto, M. Boiocchi, E. Olivetti, M. Mantegazza, F. Magistrelli, M. Badà, V. Luoni, P. E. Frossard, L. P. Lopez, and A. Kazakov. 2009. Ballistic and mechanical characterization of solid fuels for hybrid rocket. 4ème Séminaire PERSEUS. Paris, France.

17. Boiocchi, M., G. Gariani, L. Merotto, C. Paravan, A. Reina, A. Bandera, F. Maggi, L. Galfetti, G. Colombo, and L. T. DeLuca. 2010. Time-resolved characterization of solid fuel burning for hybrid propulsion. 5ème Séminaire PERSEUS. Paris, France.

18. Houser T. J., and M. V. Peck. 1964. Research in hybrid combustion. In: Heterogeneous combustion. Eds. H. G. Wolfhard, I. Glassman, and L. Green, Jr. Progress in astronautics and aeronautics ser. New York: Academic Press. 15:559-81. 
19. De Zilwa, S., G. Ziliac, M. Reinath, and A. Karabeyoglu. 2004. Time-resolved fuel-grain port diameter measurement in hybrid rockets. J. Propul. Power 20(4).

20. Cauty, F., N. Serin, and D. Gramer. 2007. Solid fuel pyrolysis phenomena and regression rate, Part 2: Measurement techniques. In: Fundamentals of hybrid rocket combustion and propulsion. Eds. M. J. Chiaverini and K. K. Kuo. Progress in aeronautics and astronautics ser. 218(4):167-205.

21. Evans, B., N. Favorito, and K. K. Kuo. 2005. Study of solid fuel burning rate enhancement behavior in an X-ray translucent hybrid rocket motor. AIAA Paper No. 2005-3909.

22. Marxman, G. A., and M. Gilbert. 1963. Turbulent boundary layer combustion in the hybrid rocket. 9th Symposium (International) on Combustion Proceedings. New York: Academic Press. 371-83.

23. DeLuca, L. T. 2009. Problemi energetici in propulsione aerospaziale. Politecnico di Milano, Appunti per Studenti - Edizione Preliminare Corretta ed Estesa, Premani, Pantigliate. Milano, Italy. 12:33-74.

24. Evans, B., N.A. Favorito, and K. K. Kuo. 2006. Oxidizer-type and aluminumparticle addition effects on solid-fuel burning behavior. AIAA Paper No. 2006-4676.

25. OpenFOAM. 2008. The OpenSource CFD Toolbok. User Guide. Version 1.5.

26. Veynante, D., and L. Vervisch. 2002. Turbulent combustion modeling. Prog. Energy Combust. Sci. 28:193-266.

27. Siegel, R., and J. Howell. Thermal radiation heat transfer. 1981. New York: McGraw-Hill.

28. Arisawa, H., and T. B. Brill. 1996. Flash pyrolysis of hydroxil-terminated polybutadiene (HTPB) I: Analysis and implications of the gaseous products. Combust. Flame 106(1-2):131-43.

29. Strand, L. D., R. L. Ray, and F. Anderson. 1994. Characterization of hybrid rocket internal heat flux and HTPB fuel pyrolysis. AIAA Paper No. 94-2876.

30. Chiaverini, M. J., N. Serin, D. K. Johnson, Y. C. Lu, K. K. Kuo, and G. A. Risha. 2000. Regression rate behavior of hybrid rocket solid fuels. J. Propul. Power 16(1).

31. Sankaran, V., and C. Merkle. 1996. Size scale-up in hybrid rocket motors. AIAA Paper No. 96-0647.

32. Glassman, I., and R.F. Sawyer. 1970. The performance of chemical propellants. AGARDograph, AGARD. No. 129.

33. Smith, E. B. 2005. Basic chemical thermodynamics. 5th ed. London: Imperial College Press.

34. Gordon, S., and B. McBride. 1994. Computer program for calculation of complex chemical equilibrium compositions and applications. I. Analysis. NASA. RP-1311.

35. Sheehan, C. J., and A. L. Bisio. 1966. Polymer/solvent interaction parameters. Rubber Chem. Technol. 39(2):149-92.

36. Treloar, L. R. G. 2005. The physics of rubber elasticity. In: Oxford classic texts. 3rd ed. USA: Oxford University Press.

37. 2009. DIN Standard 53504. Testing of rubber - determination of tensile strength at break, tensile stress at yield, elongation at break and stress values in a tensile test. Deutsches Institut Fur E. V. Normung 